\title{
Characterization of the Subgingival Cultivable Microbiota in Patients with Different Stages of Periodontitis in Spain and Colombia. A Cross-Sectional Study
}

\author{
Roquelina Pianeta ${ }^{1,2}$, Margarita Iniesta ${ }^{1, * \mathbb{D}}$, Diana Marcela Castillo ${ }^{3} \mathbb{D}$, Gloria I. Lafaurie ${ }^{3}$, Mariano Sanz $^{1}$ \\ and David Herrera ${ }^{1}$ (D) \\ 1 ETEP (Etiology and Therapy of Periodontal and Peri-Implant Diseases) Research Group, Faculty of \\ Odontology, University Complutense of Madrid (UCM), 28040 Madrid, Spain; rpianeta@ucm.es (R.P.), \\ marsan@ucm.es (M.S.); davidher@ucm.es (D.H.) \\ 2 School of Dentistry, Corporación Universitaria Rafael Núñez (CURN), 10003 Cartagena, Colombia \\ 3 Unit of Basic Oral Investigation (UIBO), School of Dentistry, Universidad El Bosque (UEB), \\ 110121 Bogotá, Colombia; castillodiana@unbosque.edu.co (D.M.C.); \\ lafauriegloria@unbosque.edu.co (G.I.L.) \\ * Correspondence: margaini@ucm.es
}

Citation: Pianeta, R.; Iniesta, M.; Castillo, D.M.; Lafaurie, G.I.; Sanz, M.; Herrera, D. Characterization of the Subgingival Cultivable Microbiota in Patients with Different Stages of Periodontitis in Spain and Colombia. A Cross-Sectional Study. Microorganisms 2021, 9, 1940. https://doi.org/10.3390/ microorganisms 9091940

Academic Editor:

Sofia Costa-de-Oliveira

Received: 28 July 2021

Accepted: 11 September 2021

Published: 12 September 2021

Publisher's Note: MDPI stays neutral with regard to jurisdictional claims in published maps and institutional affiliations.

Copyright: (c) 2021 by the authors. Licensee MDPI, Basel, Switzerland. This article is an open access article distributed under the terms and conditions of the Creative Commons Attribution (CC BY) license (https:/ / creativecommons.org/licenses/by/ $4.0 /)$.

\begin{abstract}
The objective was to characterize and compare the subgingival microbiota in patients diagnosed according to the World Workshop on the Classification of Periodontal and Peri-Implant Diseases and Conditions 2018. For this cross-sectional study, Spanish and Colombian subjects (characterized as health/gingivitis, periodontitis in stages I-II or stages III-IV) were clinically assessed, and subgingival samples were taken and processed by culture. The comparisons among patients with periodontal status (and between countries) was made using Mann-Whitney, Kruskal-Wallis, ANOVA and chi-square tests. The final sample consisted of 167 subjects. Eikenella corrodens and Parvimonas micra were more frequently detected in health/gingivitis and Porphyromonas gingivalis in periodontitis $(p<0.05)$. Higher total counts were observed in Colombia $(p=0.036)$. In Spain, significantly higher levels of P. gingivalis and Campylobacter rectus were observed, and of Tannerella forsythia, P. micra, Prevotella intermedia, Fusobacterium nucleatum, Actinomyces odontolyticus and Capnocytophaga spp. in Colombia $(p<0.001)$. P. micra was more prevalent in health/gingivitis and stage I-II periodontitis in Colombia, and P. gingivalis in all periodontitis groups in Spain $(p<0.05)$. As conclusions, significant differences were detected in the microbiota between health/gingivitis and periodontitis, with minor differences between stages of periodontitis. Differences were also relevant between countries, with Colombia showing larger counts and variability of bacterial species.
\end{abstract}

Keywords: periodontitis; subgingival microbiota; microbiological culture; Spain; Colombia

\section{Introduction}

Periodontitis is a multifactorial chronic inflammatory disease [1,2], with a complex polymicrobial aetiology [3,4]. This disease is highly prevalent affecting large proportions of adults in different populations, depending on economic, cultural, social, and ethnic factors $[5,6]$. Periodontitis has recently been classified in stages and grades following the criteria of the World Workshop on the Classification of Periodontal and Peri-Implant Diseases and Conditions [1,2].

Bacterial communities organized in subgingival biofilms are the primary etiological factor of periodontitis [7,8]. These bacterial communities mainly result from ecological changes in their structure and the increase in total microbial biomass [3]. More than 700 different bacterial species have been identified in the subgingival microbiota $[7,9,10]$, among which some have an effect on the general community that is much greater than the biomass they occupy, called key pathogens $[3,11]$. It is believed that some of these pathobionts, despite being present in low abundance in periodontitis, would produce the 
maturation of potentially pathogenic communities [3,4,11], which would transform a symbiotic microbiota into a dysbiotic one, breaking homeostasis and producing inflammation and tissue destruction [4,11].

However, studies evaluating the composition of the subgingival microbiota have resulted in a high heterogeneity, probably due to the variability in the case definitions used to select periodontitis patients [12] and sociodemographic or geographic differences [9,13], including differences in ethnicity of the populations evaluated [14] or in the age [15]. In fact, previous investigations from our research groups have reported significant differences in the prevalence and proportions of periodontal pathogens when comparing different geographical areas, using the same microbiological diagnostic techniques [13,16-19]. In these studies, a comparison between the periodontal microbiota of Dutch and Spanish patients was presented, and a lower prevalence of Aggregatibacter actinomycetemcomitans was observed in Spain [19]. When Spanish and Colombian patients were compared, Porphyromonas gingivalis was more frequent in periodontitis in Spanish patients than in Colombian patients [13]. Thus, the hypothesis arose that the present study could also be able to find differences between the studied populations, although this has to be confirmed using the criteria of the current classification.

Molecular selective techniques, including checkerboard DNA-DNA hybridization, real-time polymerase chain reaction (PCR), human oral microbe identification microarrays (HOMIM), oligonucleotide DNA-DNA hybridization, RNA-oligonucleotide quantification technique (ROQT), and techniques that allow the sequencing of the entire genome, such as pyrosequencing or next-generation sequencing (NGS) $[7,12]$ have contributed to the characterization of periodontal microbiota, but its exclusive use could result in incomplete data on microbial diversity and, therefore, it is important to have parallel culture libraries $[7,20]$. Despite the fact that molecular detection techniques have greatly contributed to the knowledge of the periodontal microbiota, different studies criticize the total dependence on this type of tests, because they may underestimate a century of culture history. It has been proven that the culture is able to better detect bacterial diversity, compared to molecular methods, in addition to allowing the operator to see what has not been amplified. Perhaps, due to the analysis of the aforementioned, some researchers have turned to the use of the culture alone or in combination with other bacterial characterization techniques [7]. Due to the introduction of more competent anaerobic handling and incubation procedures, the culture is reinvented every day [17]. Thus, among many new perspectives, culture has become the basis for a high-throughput microbiological test alternative (culturomics) that have already been used in the identification of oral pathogens [21]. That is why cultivation continues to be an interesting alternative for microbiological testing [22].

The advent of the new classification of periodontitis in stages and grades [1], facilitates an adequate categorization of periodontitis patients and highlights the need of characterizing the subgingival microbiota using different microbiological methods, including anaerobic culture [21] that allows for comparisons with classical studies of prevalence and relative proportions of well-established periodontal pathogens [23].

Hence, the objective of the present study was to characterize and compare the subgingival cultivable microbiota, according to the criteria of the 2018 classification of periodontitis cases, in subjects from two different geographical locations (Spain and Colombia).

\section{Materials and Methods}

The present cross-sectional study was approved by the local ethical committees (references 18/127-E in Spain and 012-2018 in Colombia), and all recruited patients granted their authorization by signing the approved informed consent. All aspects of the Helsinki Declaration regarding experimentation involving human beings were considered. This manuscript follows the Strengthening the Reporting of Observational Studies in Epidemiology (STROBE) guidelines for reporting cross-sectional studies [24]. 


\subsection{Subjects}

The study was carried out in subjects attending the clinics of the Dental Schools at El Bosque University (UIBO) in Bogotá, Colombia, and University Complutense of Madrid (UCM), Spain. Patients were selected from April 2018 to March 2020, according to the following criteria:

\subsubsection{Inclusion Criteria}

Adults from 30 to 60 years old were included in the study, categorized by their periodontal conditions, according to the following criteria:

- Health and gingivitis subjects, as controls. No clinical attachment loss (CAL) nor radiographical bone loss (RBL) and probing depths (PD) $\leq 3 \mathrm{~mm}$, assuming no pseudo pockets [25].

- Periodontitis in stages I or II. Following the criteria for severity, interdental CAL of 1-2 mm (stage I) or 3-4 mm (stage II) and RBL affecting only the coronal third of the root (<15\% for stage I and 15-33\% for stage II) [2].

- Periodontitis in stages III or IV. Following the criteria for severity, interdental CAL $\geq 5 \mathrm{~mm}$ and RBL extending to middle or apical third of the root. There should be evidence of tooth loss $\leq 4$ teeth due to periodontal reasons in stage III, and $\geq 5$ teeth in stage IV [2]. If needed, and using the criteria for complexity, furcation involvement class II or III.

\subsubsection{Exclusion Criteria}

- Periodontal treatment in the previous year.

- Acute periodontal conditions such as periodontal abscesses or necrotizing periodontal diseases, at the time of the screening.

- Having taken antibiotics in the previous 3 months.

- Systemic diseases or conditions (diabetes, quantitative and/or qualitative polymorphonuclear neutrophil defects, other immune system disorders).

- Pregnant women.

- Chronic use of anti-inflammatories, anticonvulsants, immunosuppressants, calcium channel blockers, upon sample collection for the study, or 6 months prior to the study.

\subsection{Study Visit}

Socio-demographic variables, such as age, gender, country and smoking habits, were registered. A medical questionnaire was carried out and if inclusion and exclusion criteria were fulfilled, patients were verbally informed about the study purpose and procedures, and they were asked to participate and, upon acceptance, to sign an informed consent. Each patient received a complete periodontal and radiographic examination (panoramic and/or periapical radiographs) and microbiological samples were taken.

\subsection{Clinical Variables}

Measurements were performed at six sites per tooth in all teeth, except third molars, with a UNC-15 periodontal probe (HuFriedy, Leinmen, Germany) by two calibrated examiners, one in each country. Clinical measurement from dental implants were not included in the analyses. All participants were clinically examined, including the following parameters, in order of registration:

- Gingival recession (REC), measured as the distance from the cementoenamel junction (CEJ) to the gingival margin and recorded to the nearest millimetre.

- $\quad \mathrm{PD}$, measured from the gingival margin to the bottom of the sulcus/pocket and recorded to the nearest millimetre.

- $\mathrm{CAL}$, measured as the distance from the bottom of the pocket to the CEJ.

- Bleeding on probing $(\mathrm{BoP})$, measured after probing to the base of the pocket and expressed as a percentage [26]. 
- $\quad$ Plaque index (PII), evaluated by the presence of visible dental plaque, disclosed by erythrosine staining (Plac-Control ${ }^{\circledR}$, Dentaid, Barcelona, Spain) and expressed as a percentage [27].

\subsection{Microbiological Variables}

\subsubsection{Microbiological Sampling}

Samples were taken from four selected sites, by means of two consecutive standardized 30\# sterile paper points (Maillefer, Ballaigues, Switzerland) per site. Paper points were inserted into the crevice or pocket and left in place for $10 \mathrm{~s}$. Prior to sampling, supragingival plaque was removed from the sampling site followed by isolation from saliva with the use of cotton rolls and compressed air. All paper points were transferred into a screw-capped vial, containing $1.5 \mathrm{~mL}$ of reduced transport fluid (RTF) [28] and sent to the microbiological laboratories of each centre within $24 \mathrm{~h}$. Sampling sites were selected as follows:

- In healthy/gingivitis subjects, subgingival samples were taken from the mesio-buccal sites of the first molars and, when absent, from the adjacent second molars (the next alternative was the second premolars and from there, any teeth present mesially).

- In subjects with periodontitis, subgingival samples were taken from the most accessible site with the deepest PD and BoP, per quadrant.

\subsubsection{Microbiological Processing}

At the laboratories (UCM, UIBO), samples were homogenized by vortexing for $30 \mathrm{~s}$, four serial dilutions in phosphate buffer saline (PBS) were performed, and $100 \mu \mathrm{L}$ were placed on: (i) non-selective blood agar medium (Blood Agar Base II, Oxoid, Basingstoke, U.K.), supplemented with haemin $(5 \mathrm{mg} / \mathrm{L})$, menadione $(1 \mathrm{mg} / \mathrm{L})$ and $5 \%$, sterile horse blood for determination of total anaerobic counts and for the identification of most target pathogens; and (ii) onto the selective medium Dentaid-1 [29] for isolation and quantification of $A$. actinomycetemcomitans. Blood agar plates were incubated for 14 days in anaerobic conditions $\left(80 \% \mathrm{~N}_{2}, 10 \% \mathrm{CO}_{2}\right.$ and $\left.10 \% \mathrm{H}_{2}\right)$ at $37^{\circ} \mathrm{C}$, and selective agar plates were incubated for 3 days in air with $5 \% \mathrm{CO}_{2}$ at $37{ }^{\circ} \mathrm{C}$. After incubation, initial identification of target species was done using colony morphology, and suspected colonies were further identified by microscope, Gram-staining and enzyme activity. Counts of representative colonies (those with colony morphologies compatible with target pathogen morphology) were carried out. Counting was performed in plates with 30-300 colonies.

\subsection{Statistical Analysis}

\subsubsection{Calibration}

Clinical parameters were evaluated by two calibrated examiners. An intra-examiner calibration was performed by recording duplicate measurements of PD and CAL in three patients, twice during the same visit, with $30 \mathrm{~min}$ intervals and intra-class reproducibility was calculated. The interclass correlation coefficient (ICC) showed an $86.3 \%$ of agreement for PD and $84.7 \%$ for CAL in Spain, and $90.2 \%$ and $89 \%$, respectively, in Colombia.

\subsubsection{Sample Size Calculation}

The selected outcome variable to calculate the sample size was counts of $P$. gingivalis. Based on an expected difference between healthy/gingivitis and periodontitis groups in the mean of counts (expressed as colony forming units, CFU, 2900), with a standard deviation (SD) of 3008.75 [30], an alpha error of 0.05 and a power of $90 \%, 30$ patients per group were necessary. Besides, and in order to narrow differences between different age groups in different conditions, the overall sample followed a uniform stratified sampling, in which the same size for all the defined strata was assigned. The desired sampling distribution was 30 patients for each periodontal status group (healthy and gingivitis, periodontitis in stages I or II, periodontitis in stages III or IV), and 10 patients for each age cohort (30-40 years, 41-50 years, 51-60 years, within each periodontal status category). 


\subsubsection{Statistical Analysis}

For continuous data, Kolmogorov-Smirnov test and distribution of data were used to assess normality. Clinical and microbiological data were calculated by patient and then by periodontal status group and country. The logarithmic transformation of CFU of bacterial counts was designed to normalize the data distribution. Data were expressed as means and SD, and as median and interquartile ranges (IR) for non-parametric data. Categorical data were expressed as percentages.

Periodontal status- and country-level analyses were performed. For periodontal status-level analysis, demographic data were analysed by ANOVA test for continuous variables and chi-square test for categorical data, with probability values adjusted with the Bonferroni correction, and $p$-values were multiplied by the number of comparisons (three for periodontal status and fifteen for periodontal status by country). Clinical and microbiological variables were compared by ANOVA test, for parametric data, or KruskalWallis test with Dunn-Bonferroni post hoc tests, for non-parametric data. For categorical data, chi-square test was used, with Bonferroni correction for multiplicity when was necessary. For country-level analysis, continuous demographic variables were compared with $\mathrm{t}$ test for parametric data, or U Mann-Whitney test for non-parametric data, and chi-square tests were used for categorical variables.

A stepwise forward logistic regression was performed to explore the relationship between the frequency of bacteria detection (yes/no) and the covariables of country, smoking, periodontal status and age. Periodontal health status (healthy/gingivitis, periodontitis stages I-II, periodontitis stages III-IV) was introduced as dummy variables. A second comparison with a stratification by age range was performed with country, smoking and periodontal status as covariables. Odds ratios (OR) together with the $95 \%$ confidence intervals $(\mathrm{CI})$ were calculated. All statistical analyses were performed using SPSS 20 program package (SPSS Inc, Chicago, IL, USA) and the level of significance was set in 0.05 .

\section{Results}

\subsection{Study Population}

A total of 199 patients were initially recruited, but four patients in Spain and 25 in Colombia were excluded. The reasons for exclusion in Spain were age or technical problems, and in Colombia, presenting systemic diseases, age, and having taken antibiotics in the last three months. The final sample consisted of 167 patients (Spain $n=90$ and Colombia $n=77$ ): 30 and 18, respectively, with periodontal health and gingivitis; 30 and 23, respectively, with periodontitis in stages I-II; and 30 and 36, respectively, with periodontitis in stages III-IV. In each group, three age ranges were considered: 30-40, 41-50 and 51-60 years (Table 1). Socioeconomic status was not specifically assessed. Only patients of Spanish origin (from Spain-Caucasian ethnicity) and only patients of Colombian origin (from Colombia-mixed ethnicity) were selected. Only two patients (in Spain) have received periodontal treatment in the past (subgingival instrumentation), with no supportive periodontal care for at least 3 years.

Table 1. Selected subjects ( $n$, number of patients) according to country, periodontal status group and age.

\begin{tabular}{|c|c|c|c|c|}
\hline & Periodontal Status & Age & Spain $(n)$ & Colombia $(n)$ \\
\hline Selected subjects by country & & & 90 & 77 \\
\hline \multirow{3}{*}{$\begin{array}{l}\text { Selected subjects by periodontal status } \\
\text { group and country }\end{array}$} & Health and Gingivitis & & 30 & 18 \\
\hline & Periodontitis I-II & & 30 & 23 \\
\hline & Periodontitis III-IV & & 30 & 36 \\
\hline
\end{tabular}


Table 1. Cont

\begin{tabular}{|c|c|c|c|c|}
\hline & Periodontal Status & Age & Spain $(n)$ & Colombia (n) \\
\hline \multirow{9}{*}{$\begin{array}{l}\text { Selected subjects by periodontal status } \\
\text { group, age and country }\end{array}$} & \multirow{3}{*}{ Health and Gingivitis } & $30-40$ & 10 & 7 \\
\hline & & $41-50$ & 10 & 5 \\
\hline & & $51-60$ & 10 & 6 \\
\hline & \multirow{3}{*}{ Periodontitis I-II } & $30-40$ & 10 & 11 \\
\hline & & $41-50$ & 10 & 6 \\
\hline & & $51-60$ & 10 & 6 \\
\hline & \multirow{3}{*}{ Periodontitis III-IV } & $30-40$ & 10 & 11 \\
\hline & & $41-50$ & 10 & 16 \\
\hline & & $51-60$ & 10 & 9 \\
\hline
\end{tabular}

No statistically significant differences in age $(p=0.170)$, gender $(p=0.409)$ and smoking habit $(p=0.064)$, among groups according to their periodontal status, were observed (Table 2). When comparing subjects from different countries, no significant differences in age $(p=0.242)$, or gender $(p=0.972)$ were detected, but a significantly lower percentage of smokers in Colombian patients $(9.1 \%)$, when compared with Spanish patients $(26.7 \%)$, was evidenced $(p=0.004)$. When comparing the impact of both periodontal status and country, no significant differences were observed for age and gender, while a statistically significant higher percentage of smokers, in Spanish versus Colombian subjects, was observed in stage I-II periodontitis ( $30.0 \%$ versus $4.3 \%$, respectively) $(p=0.031)$ and stage III-IV periodontitis ( $40.0 \%$ versus $11.1 \%$, respectively) ( $p=0.006)$, when compared to Colombian patients for the same periodontal status groups.

\subsection{Clinical Outcome Variables}

Statistically significant differences were observed among periodontal status groups, both for mean CAL, BoP and PD, as well as for the proportion of pockets in the categories $1-3 \mathrm{~mm}$ and $4-5 \mathrm{~mm}(p<0.001)$. For the proportion of deep pockets $(\geq 6 \mathrm{~mm})$, significant differences were only detected when comparing health-gingivitis with periodontitis I-II $(p<0.001)$, and periodontitis I-II with periodontitis III-IV $(p<0.001)$. PII only presented statistically significant differences when comparing health-gingivitis with periodontitis I-II and with periodontitis III-IV ( $p<0.001$ ) (Table 3$)$. The grade distribution of periodontitis did not show any difference among grades or between countries (Table S1).

When assessing periodontal status and country, statistically significant higher means in PD $(p=0.037)$ and BoP $(p<0.001)$, were observed in Colombian subjects in stages I-II periodontitis group, and statistically significant higher BoP values were also observed in stages III-IV periodontitis $(p=0.024)$. Conversely, higher PII $(p<0.001)$ in health/gingivitis group was observed in Spain (Table 3).

Statistically significant differences were observed among periodontal status groups, both for mean CAL, BoP, and PD, as well as for the proportion of pockets in the categories $1-3 \mathrm{~mm}$ and $4-5 \mathrm{~mm}(p<0.001)$. For the proportion of deep pockets $(\geq 6 \mathrm{~mm})$ significant differences were only detected when comparing health-gingivitis with periodontitis I-II $(p<0.001)$, and periodontitis I-II with periodontitis III-IV $(p<0.001)$. PlI only presented statistically significant differences when comparing health-gingivitis with periodontitis I-II and with periodontitis III-IV $(p<0.001)$ (Table 3). The clinical characteristics of the sampled sites were similar for all periodontal status and for both countries, except for PII, which showed significantly higher levels in the health-gingivitis group in Spain than in Colombia $(p<0.001)$ (Table S2). 
Table 2. Description of the sample population characteristics (demographic variables and smoking habit), and comparisons according to periodontal status and country.

\begin{tabular}{|c|c|c|c|c|c|c|c|c|c|c|c|c|c|c|c|}
\hline \multirow[b]{2}{*}{ Comparison } & \multirow[b]{2}{*}{$\begin{array}{c}\text { First } \\
\text { Comparison }\end{array}$} & \multirow[b]{2}{*}{$\begin{array}{c}\text { Second } \\
\text { Comparison }\end{array}$} & \multicolumn{3}{|c|}{ Age $^{a}$} & \multicolumn{5}{|c|}{ Gender $^{b}$} & \multicolumn{5}{|c|}{ Smoking ${ }^{b}$} \\
\hline & & & $n$ & $\begin{array}{l}\text { Mean } \\
\text { (SD) }\end{array}$ & $p$ Value & $n$ & $\begin{array}{c}\text { Female } \\
\%\end{array}$ & $n$ & $\begin{array}{l}\text { Male } \\
\%\end{array}$ & $p$ Value & $n$ & $\begin{array}{c}\text { Non } \\
\text { Smokers } \\
\%\end{array}$ & $n$ & $\begin{array}{c}\text { Smokers } \\
\%\end{array}$ & $p$ Value \\
\hline \multirow{3}{*}{$\begin{array}{l}\text { Periodontal } \\
\text { status group }\end{array}$} & $\begin{array}{l}\text { Health and } \\
\text { Gingivitis }\end{array}$ & & 48 & $\begin{array}{l}45.13 \\
(9.71)\end{array}$ & \multirow{3}{*}{0.170} & 26 & 54.2 & 22 & 45.8 & \multirow{3}{*}{0.409} & 43 & 89.6 & 5 & 10.4 & \multirow{3}{*}{0.064} \\
\hline & Periodontitis I-II & & 53 & $\begin{array}{l}43.72 \\
(8.77)\end{array}$ & & 30 & 56.6 & 23 & 43.4 & & 43 & 81.1 & 10 & 18.9 & \\
\hline & $\begin{array}{l}\text { Periodontitis } \\
\text { III-IV }\end{array}$ & & 66 & $\begin{array}{l}45.32 \\
(8.00)\end{array}$ & & 31 & 47.0 & 35 & 53.0 & & 50 & 75.8 & 16 & 24.2 & \\
\hline \multirow{5}{*}{$\begin{array}{l}\text { Periodontal } \\
\text { status by country }\end{array}$} & $\begin{array}{l}\text { Health and } \\
\text { Gingivitis }\end{array}$ & Spain & 30 & $\begin{array}{l}44.97 \\
(8.28)\end{array}$ & \multirow{5}{*}{0.588} & 16 & 53.3 & 14 & 46.7 & \multirow{5}{*}{1.000} & 27 & 90.0 & 3 & 10.0 & \multirow{5}{*}{$\begin{array}{c}0.045, \\
\text { Periodontitis } \\
\text { I-II (Colombia) } \\
\text { versus } \\
\text { Periodontitis } \\
\text { III-IV (Spain) }\end{array}$} \\
\hline & & Colombia & 18 & $\begin{array}{c}45.39 \\
(11.99)\end{array}$ & & 10 & 55.6 & 8 & 44.4 & & 16 & 88.9 & 2 & 11.1 & \\
\hline & Periodontitis I-II & Spain & 30 & $\begin{array}{l}45.17 \\
(8.04)\end{array}$ & & 16 & 53.3 & 14 & 46.7 & & 21 & 70.0 & 9 & 30.0 & \\
\hline & \multirow{2}{*}{$\begin{array}{l}\text { Periodontitis } \\
\text { III-IV }\end{array}$} & Colombia & 23 & $\begin{array}{l}41.83 \\
(9.49)\end{array}$ & & 14 & 60.9 & 9 & 39.1 & & 22 & 95.7 & 1 & 4.3 & \\
\hline & & Colombia & 36 & $\begin{array}{l}44.47 \\
(7.81)\end{array}$ & & 16 & 44.4 & 20 & 55.6 & & 32 & 88.9 & 4 & 11.1 & \\
\hline
\end{tabular}

$\mathrm{SD}$, standard deviation; $n$, number of patients. ${ }^{\mathrm{a}}$, One-way ANOVA test. ${ }^{\mathrm{b}}$, chi-square test with Bonferroni correction. 
Table 3. Comparison of clinical parameters between countries (first comparison) and among periodontal status groups (second comparison).

\begin{tabular}{|c|c|c|c|c|c|c|c|c|c|c|c|}
\hline & \multirow[b]{2}{*}{$\begin{array}{c}\text { First } \\
\text { Comparison }\end{array}$} & \multicolumn{3}{|c|}{ Health and Gingivitis a } & \multicolumn{3}{|c|}{ 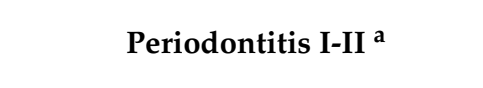 } & \multicolumn{3}{|c|}{ Periodontitis III-IV $^{a}$} & \multirow{2}{*}{$\begin{array}{c}\begin{array}{c}\text { Second Comparison } \\
\text { (among Periodontal Status }\end{array}{ }^{\text {b }} \text { ) } \\
p \text { Value }\end{array}$} \\
\hline & & $n$ & Mean (SD) & $p$ Value & $n$ & Mean (SD) & $p$ Value & $n$ & Mean (SD) & $p$ Value & \\
\hline PD (mm) & $\begin{array}{l}\text { Spain } \\
\text { Colombia }\end{array}$ & $\begin{array}{l}30 \\
18\end{array}$ & $\begin{array}{l}2.26(0.31) \\
2.17(0.27)\end{array}$ & 0.359 & $\begin{array}{l}30 \\
23\end{array}$ & $\begin{array}{l}2.90(0.39) \\
3.19(0.57)\end{array}$ & 0.037 & $\begin{array}{l}30 \\
36\end{array}$ & $\begin{array}{l}4.04(0.76) \\
3.72(0.65)\end{array}$ & 0.069 & $<0.001$ \\
\hline $\begin{array}{c}\text { PD 1-3 mm } \\
(\%)\end{array}$ & $\begin{array}{c}\text { Spain } \\
\text { Colombia }\end{array}$ & $\begin{array}{l}30 \\
18 \\
\end{array}$ & $\begin{array}{c}98.37(3.14) \\
94.83(12.62)\end{array}$ & 0.148 & $\begin{array}{l}30 \\
23 \\
\end{array}$ & $\begin{array}{l}77.38(14.17) \\
68.42(21.38) \\
\end{array}$ & 0.073 & $\begin{array}{l}30 \\
36\end{array}$ & $\begin{array}{c}43.08(21.77) \\
50.19(9.73)\end{array}$ & 0.083 & $<0.001$ \\
\hline$P \underset{(\%)}{\geq 6 \mathrm{~mm}}$ & Colombia & 30 & $0.01(0.10)$ & 0.445 & 30 & $1.82(2.06)$ & 0.174 & 30 & $18.86(14.52)$ & 0.424 & $\begin{array}{c}<0.001, \text { Health and Gingivitis versus } \\
\text { Periodontitis III-IV } \\
<0.001, \text { Periodontitis I-II versus } \\
\text { Periodontitis III-IV }\end{array}$ \\
\hline CAL (mm) & $\begin{array}{l}\text { Spain } \\
\text { Colombia }\end{array}$ & $\begin{array}{l}30 \\
18\end{array}$ & $\begin{array}{l}0.33(0.24) \\
0.28(0.26)\end{array}$ & 0.521 & $\begin{array}{l}30 \\
23\end{array}$ & $\begin{array}{l}3.07(0.39) \\
3.16(0.96)\end{array}$ & 0.660 & $\begin{array}{l}30 \\
36\end{array}$ & $\begin{array}{l}4.78(0.85) \\
4.52(0.93)\end{array}$ & 0.237 & $<0.001$ \\
\hline PII (\%) & Colombia & 30 & $50.97(25.07)$ & $<0.001$ & 23 & $62.69(25.59)$ & 0.736 & 30 & $70.27(36.49)$ & 0.465 & $\begin{array}{l}<0.001, \text { Health and Gingivitis versus } \\
\text { Periodontitis I-II } \\
<0.001, \text { Health and Gingivitis versus } \\
\text { Periodontitis III-IV }\end{array}$ \\
\hline
\end{tabular}

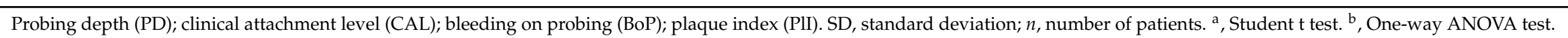




\subsection{Subgingival Cultivable Microbiota-Total Anaerobic Counts}

Statistically significant lower total anaerobic counts were observed for the health/gingivitis group, when compared with stages I-II periodontitis $(p=0.029)$, and stages III-IV periodontitis $(p=0.010)$. Overall, significantly higher counts were observed in Colombian patients $(p=0.036)$, together with a lower range of variability. When comparing the impact of both periodontal status and country, statistically significant higher counts were observed in Colombia for the health/gingivitis group $(p=0.001)$, when compared with Spain (Table 4$)$.

\subsection{Subgingival Cultivable Microbiota-Periodontal Pathogens}

Overall, the most frequently detected bacterial species were $P$. gingivalis, Tannerella forsythia, Parvimonas micra, Capnocytophaga spp., and Actinomyces odontolyticus. These pathogenic species, together with Fusobacterium nucleatum were also present in relatively high counts and proportions. A. actinomycetemcomitans was not detected in any of the samples studied. Statistically significant higher counts, proportions, and frequency of detection of P. gingivalis for, stages I-II periodontitis when compared with health/gingivitis $(p \leq 0.05)$, were observed. The opposite was true for Eikenella corrodens, with lower values and frequency of detection in stages III-IV periodontitis, when compared with health/gingivitis $(p \leq 0.05)$. In addition, P. micra showed statistically significant lower counts $(p=0.006)$, proportions $(p=0.009)$ and frequency of detection $(p=0.009)$, in periodontitis stages III-IV, as compared with health/gingivitis (Table 5). When comparing countries, statistically significant higher counts, proportions, and frequency of detection of $P$. gingivalis and Campylobacter rectus were observed in Spain $(p<0.001)$. Conversely, samples from Colombian patients showed significant higher counts, proportions, and frequency of detection of T. forsythia, P. micra, Capnocytophaga spp. and A. odontolyticus $(p<0.001)$, and counts and proportions of Prevotella intermedia and F. nucleatum ( $p \leq 0.05$ ) (Table 5). When assessing the impact of both periodontal status and country, for stages I-II periodontitis (Table S3), counts, and proportions of $F$. nucleatum, and proportions and frequency of detection of P. micra, Capnocytophaga spp. and A. odontolyticus were significantly higher in Colombian patients, compared with Spanish patients, who showed a higher frequency of detection of P. gingivalis $(p<0.001)$ and P. intermedia $(p=0.014)$, and higher counts, proportions, and detection frequencies of E. corrodens ( $p \leq 0.05$ ). For stages III-IV periodontitis (Table S4), counts, proportions and frequency of detection of Capnocytophaga spp. and A. odontolyticus were higher in Colombia, in contrast to higher frequency of detection of $P$. gingivalis $(p \leq 0.05)$ in Spain. In the health/gingivitis group (Table S5), significantly higher counts, proportions, and frequency of detection of P. intermedia, T. forsythia, P. micra, Capnocytophaga spp., and A. odontolyticus, in addition to higher counts of F. nucleatum, were observed in Colombia $(p \leq 0.05)$. 
Table 4. Comparison of total anaerobic counts (log transformed) among periodontal status groups (first comparison) and between countries (second comparison).

\begin{tabular}{|c|c|c|c|c|c|c|c|c|}
\hline \multirow{2}{*}{ Comparison } & \multirow{2}{*}{$\begin{array}{c}\text { First } \\
\text { Comparison }\end{array}$} & \multirow{2}{*}{$\begin{array}{c}\text { Second } \\
\text { Comparison }\end{array}$} & \multirow{2}{*}{$n$} & \multirow{2}{*}{ Mean (SD) } & \multirow{2}{*}{ Mean Difference } & \multicolumn{2}{|c|}{$95 \%$ CI } & \multirow{2}{*}{$p$ Value $^{\mathrm{a}}$} \\
\hline & & & & & & Lower Bound & Upper Bound & \\
\hline \multirow{3}{*}{$\begin{array}{l}\text { Periodontal } \\
\text { status group }\end{array}$} & $\begin{array}{l}\text { Health and } \\
\text { Gingivitis }\end{array}$ & & 48 & $6.29(0.73)$ & $-0.31 *$ & -0.60 & -0.02 & 0.029 \\
\hline & Periodontitis I-II & & 53 & $6.60(0.55)$ & $-0.02^{\dagger}$ & -0.29 & 0.24 & 1.000 \\
\hline & Periodontitis III-IV & & 66 & $6.63(0.53)$ & $-0.34 \ddagger$ & -0.61 & -0.60 & 0.010 \\
\hline Country & & $\begin{array}{l}\text { Spain } \\
\text { Colombia }\end{array}$ & $\begin{array}{l}90 \\
77\end{array}$ & $\begin{array}{l}6.43(0.64) \\
6.63(0.56)\end{array}$ & $-0.20^{\S}$ & -0.38 & -0.01 & 0.036 \\
\hline \multirow{5}{*}{$\begin{array}{c}\text { Periodontal } \\
\text { status by country }\end{array}$} & $\begin{array}{l}\text { Health and } \\
\text { Gingivitis }\end{array}$ & Spain & 30 & $5.99(0.67)$ & \multirow[t]{2}{*}{$-0.80^{\S}$} & \multirow[t]{2}{*}{-1.18} & \multirow[t]{2}{*}{-0.43} & \multirow[t]{2}{*}{$<0.001$} \\
\hline & \multirow[b]{2}{*}{ Periodontitis I-II } & Colombia & 18 & $6.79(0.51)$ & & & & \\
\hline & & Spain & 30 & $6.57(0.46)$ & $-0.09 \S$ & \multirow{2}{*}{-0.40} & \multirow{2}{*}{0.22} & \multirow{2}{*}{0.565} \\
\hline & \multirow{2}{*}{ Periodontitis III-IV } & $\begin{array}{l}\text { Colombia } \\
\text { Spain }\end{array}$ & $\begin{array}{l}23 \\
30\end{array}$ & $\begin{array}{l}6.66(0.67) \\
6.74(0.53)\end{array}$ & \multirow[b]{2}{*}{$0.20 \S$} & & & \\
\hline & & Colombia & 36 & $6.54(0.51)$ & & -0.05 & 0.46 & 0.115 \\
\hline
\end{tabular}

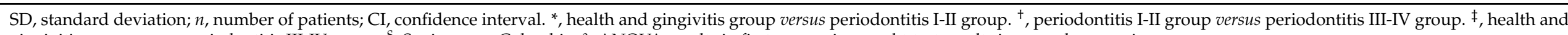
gingivitis group versus periodontitis III-IV group. $\$$, Spain versus Colombia. a , ANOVA results in first comparison and t-test results in second comparison.

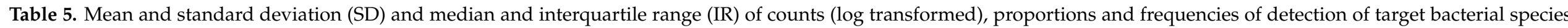
according to periodontal status and country. Counts and proportions were calculated considering all samples.

\begin{tabular}{|c|c|c|c|c|c|c|c|c|c|c|c|c|}
\hline & \multirow{2}{*}{$\begin{array}{l}\text { Periodontal Status } \\
\text { (Group) }\end{array}$} & \multirow[b]{2}{*}{ Country } & \multicolumn{4}{|c|}{ Counts $^{a}$} & \multicolumn{4}{|c|}{ Proportions $^{a}$} & \multicolumn{2}{|c|}{ Frequency $^{b}$} \\
\hline & & & $n$ & Mean (SD) & $\begin{array}{l}\text { Median } \\
\text { (IR) }\end{array}$ & $p$ Value & $n$ & Mean (SD) & $\begin{array}{l}\text { Median } \\
\text { (IR) }\end{array}$ & $p$ Value & $n(\%)$ & $p$ Value \\
\hline \multirow[t]{5}{*}{$\begin{array}{l}\text { Porphyromonas } \\
\text { gingivalis }\end{array}$} & Health and Gingivitis & & 48 & $2.34(2.66)$ & $0.00(5.48)$ & $0.014 *$ & 48 & $5.88(12.22)$ & $0.00(6.75)$ & $0.007 *$ & $22(45.8)$ & $0.006^{*}$ \\
\hline & Periodontitis I-II & & 53 & $4.15(2.51)$ & $5.00(3.77)$ & $1.000^{\dagger}$ & 53 & $\begin{array}{c}14.57 \\
(20.67)\end{array}$ & $3.72(18.50)$ & $0.512^{+}$ & $40(75.5)$ & $0.123^{+}$ \\
\hline & Periodontitis III-IV & & 66 & $3.38(2.97)$ & $5.00(6.07)$ & $0.062 \ddagger$ & 66 & $\begin{array}{c}10.28 \\
(15.08)\end{array}$ & $3.27(17.29)$ & $0.195 \ddagger$ & $38(57.6)$ & $0.645 \ddagger$ \\
\hline & & Spain & 90 & $4.34(2.33)$ & $5.12(1.95)$ & \multirow{2}{*}{$<0.001 \S$} & 90 & $\begin{array}{c}13.28 \\
(17.52)\end{array}$ & $5.83(18.16)$ & \multirow{2}{*}{$<0.001 \S$} & $72(80.0)$ & \multirow[t]{2}{*}{$<0.001 \S$} \\
\hline & & Colombia & 77 & $2.14(2.88)$ & $0.00(5.60)$ & & 77 & $6.99(14.93)$ & $0.00(5.06)$ & & $28(36.4)$ & \\
\hline
\end{tabular}


Table 5. Cont.

\begin{tabular}{|c|c|c|c|c|c|c|c|c|c|c|c|c|}
\hline & \multirow{2}{*}{$\begin{array}{l}\text { Periodontal Status } \\
\text { (Group) }\end{array}$} & \multirow[b]{2}{*}{ Country } & \multicolumn{4}{|c|}{ Counts ${ }^{a}$} & \multicolumn{4}{|c|}{ Proportions $^{a}$} & \multicolumn{2}{|c|}{ Frequency $^{\mathbf{b}}$} \\
\hline & & & $n$ & Mean (SD) & $\begin{array}{l}\text { Median } \\
\text { (IR) }\end{array}$ & $p$ Value & $n$ & Mean (SD) & $\begin{array}{l}\text { Median } \\
\text { (IR) }\end{array}$ & $p$ Value & $n(\%)$ & $p$ Value \\
\hline \multirow{5}{*}{$\begin{array}{l}\text { Prevotella } \\
\text { intermedia }\end{array}$} & Health and Gingivitis & & 48 & $3.55(2.48)$ & $4.15(5.78)$ & \multirow{3}{*}{0.294} & 48 & $5.59(8.59)$ & $0.92(5.22)$ & \multirow{3}{*}{0.497} & $35(72.9)$ & $0.978 *$ \\
\hline & Periodontitis I-II & & 53 & $3.95(2.11)$ & $4.69(2.24)$ & & 53 & $4.97(8.48)$ & $0.90(5.66)$ & & $43(81.1)$ & $1.000^{\dagger}$ \\
\hline & Periodontitis III-IV & & 66 & $4.17(2.30)$ & $5.00(1.95)$ & & 66 & $7.15(10.24)$ & $2.33(12.11)$ & & $52(78.8)$ & $1.000 \ddagger$ \\
\hline & & Spain & 90 & $3.56(2.14)$ & $4.00(2.77)$ & \multirow[b]{2}{*}{$<0.001^{\S}$} & 90 & $3.16(6.39)$ & $0.66(3.33)$ & \multirow[b]{2}{*}{$<0.001^{\S}$} & $70(77.8)$ & \\
\hline & & Colombia & 77 & $4.35(2.41)$ & $5.43(1.75)$ & & 77 & $9.35(10.86)$ & 5.11 (13.59) & & $60(77.9)$ & $0.982 \S$ \\
\hline \multirow[t]{5}{*}{$\begin{array}{l}\text { Tannerella } \\
\text { forsythia }\end{array}$} & Health and Gingivitis & & 48 & $2.33(2.73)$ & $0.00(5.58)$ & \multirow{3}{*}{0.335} & 48 & $3.84(7.10)$ & $0.00(5.31)$ & \multirow{3}{*}{0.160} & $21(43.8)$ & $0.939 *$ \\
\hline & Periodontitis I-II & & 53 & $1.72(2.45)$ & $0.00(4.65)$ & & 53 & $0.89(1.87)$ & $0.00(0.79)$ & & $18(34.0)$ & $1.000^{+}$ \\
\hline & Periodontitis III-IV & & 66 & $1.83(2.47)$ & $0.00(4.81)$ & & 66 & $0.87(1.77)$ & $0.00(1.02)$ & & $24(36.4)$ & $1.000 \ddagger$ \\
\hline & & Spain & 90 & $1.40(2.18)$ & $0.00(4.30)$ & \multirow[b]{2}{*}{$<0.001 \S$} & 90 & $0.57(1.63)$ & $0.00(0.65)$ & \multirow[b]{2}{*}{$<0.001 \S$} & $27(30.0)$ & \\
\hline & & Colombia & 77 & $2.57(2.78)$ & $0.00(5.60)$ & & 77 & $3.09(5.79)$ & $0.00(3.70)$ & & $36(46.8)$ & $0.026^{\S}$ \\
\hline \multirow{4}{*}{$\begin{array}{l}\text { Parvimonas } \\
\text { micra }\end{array}$} & Health and Gingivitis & & 48 & $1.77(2.57)$ & $0.00(5.03)$ & $0.503 *$ & 48 & $2.34(6.27)$ & $0.00(2.41)$ & $0.633 *$ & $16(33.3)$ & 1.000 * \\
\hline & Periodontitis I-II & & 53 & $1.19(2.23)$ & $0.00(0.00)$ & $0.275^{+}$ & 53 & $1.57(4.12)$ & $0.00(0.00)$ & $0.271^{+}$ & $12(22.6)$ & $0.225^{\dagger}$ \\
\hline & & Spain & 90 & $0.42(1.36)$ & $0.00(0.00)$ & \multirow[b]{2}{*}{$<0.001 \S$} & 90 & $0.28(1.59)$ & $0.00(0.00)$ & \multirow[b]{2}{*}{$<0.001 \S$} & $8(8.9)$ & \\
\hline & & Colombia & 77 & $1.88(2.61)$ & $0.00(5.14)$ & & 77 & $2.70(6.04)$ & $0.00(3.26)$ & & $27(35.1)$ & $<0.001 \S$ \\
\hline \multirow[t]{5}{*}{$\begin{array}{c}\text { Fusobacterium } \\
\text { nucleatum }\end{array}$} & Health and Gingivitis & & 48 & $4.48(1.24)$ & $4.69(1.13)$ & \multirow{3}{*}{0.111} & 48 & $3.63(3.37)$ & $2.58(4.19)$ & \multirow{3}{*}{0.951} & $46(95.8)$ & 0.822 * \\
\hline & Periodontitis I-II & & 53 & $4.52(1.74)$ & $5.04(1.08)$ & & 53 & $4.66(5.53)$ & $2.45(5.15)$ & & 47 (88.7) & $1.000^{\dagger}$ \\
\hline & Periodontitis III-IV & & 66 & $4.54(1.91)$ & $5.00(1.14)$ & & 66 & $8.24(13.55)$ & $2.65(9.20)$ & & $58(87.9)$ & $0.564 \ddagger$ \\
\hline & & Spain & 90 & $4.16(1.58)$ & $4.60(1.04)$ & \multirow{2}{*}{$<0.001 \S$} & 90 & $2.58(2.90)$ & $1.95(2.97)$ & \multirow{2}{*}{$<0.001 \S$} & $81(90.0)$ & \\
\hline & & Colombia & 77 & $4.94(1.71)$ & $5.39(1.19)$ & & 77 & $9.52(12.57)$ & $4.17(9.06)$ & & $70(90.9)$ & $0.842^{\S}$ \\
\hline
\end{tabular}


Table 5. Cont.

\begin{tabular}{|c|c|c|c|c|c|c|c|c|c|c|c|c|}
\hline & \multirow{2}{*}{$\begin{array}{l}\text { Periodontal Status } \\
\text { (Group) }\end{array}$} & \multirow{2}{*}{ Country } & \multicolumn{4}{|c|}{ Counts $^{a}$} & \multicolumn{4}{|c|}{ Proportions $^{a}$} & \multicolumn{2}{|c|}{ Frequency $^{b}$} \\
\hline & & & $n$ & Mean (SD) & $\begin{array}{l}\text { Median } \\
\text { (IR) }\end{array}$ & $p$ Value & $n$ & Mean (SD) & $\begin{array}{l}\text { Median } \\
\text { (IR) }\end{array}$ & $p$ Value & $n(\%)$ & $p$ Value \\
\hline \multirow{5}{*}{$\begin{array}{l}\text { Campylobacter } \\
\text { rectus }\end{array}$} & Health and Gingivitis & & 48 & $0.23(0.91)$ & $0.00(0.00)$ & \multirow{3}{*}{0.876} & 48 & $0.18(0.88)$ & $0.00(0.00)$ & \multirow{3}{*}{0.849} & $3(6.3)$ & $1.000 *$ \\
\hline & Periodontitis I-II & & 53 & $0.20(1.03)$ & $0.00(0.00)$ & & 53 & $0.53(3.42)$ & $0.00(0.00)$ & & $2(3.8)$ & $1.000^{\dagger}$ \\
\hline & Periodontitis III-IV & & 66 & $0.20(0.94)$ & $0.00(0.00)$ & & 66 & $0.07(0.37)$ & $0.00(0.00)$ & & $3(4.5)$ & $1.000 \ddagger$ \\
\hline & & Spain & 90 & $0.39(1.28)$ & $0.00(0.00)$ & \multirow[b]{2}{*}{$<0.001 \S$} & 90 & $0.46(2.70)$ & $0.00(0.00)$ & \multirow{2}{*}{$<0.001 \S$} & $8(8.9)$ & \\
\hline & & Colombia & 77 & $0.00(0.00)$ & $0.00(0.00)$ & & 77 & $0.00(0.00)$ & $0.00(0.00)$ & & $0(0.0)$ & $0.008^{\S}$ \\
\hline \multirow{5}{*}{$\begin{array}{l}\text { Eikenella } \\
\text { corrodens }\end{array}$} & Health and Gingivitis & & 48 & $1.03(1.89)$ & $0.00(2.25)$ & $0.048 *$ & 48 & $0.35(0.91)$ & $0.00(0.09)$ & $0.039 *$ & $12(25.0)$ & $0.051 *$ \\
\hline & Periodontitis I-II & & 53 & $0.37(1.18)$ & $0.00(0.00)$ & $1.000^{\dagger}$ & 53 & $0.07(0.37)$ & $0.00(0.00)$ & $1.000^{\dagger}$ & $5(9.4)$ & $1.000^{\dagger}$ \\
\hline & Periodontitis III-IV & & 66 & $0.47(1.53)$ & $0.00(0.00)$ & $0.074 \ddagger$ & 66 & $0.45(1.85)$ & $0.00(0.00)$ & $0.066 \ddagger$ & $6(9.1)$ & $0.033 \ddagger$ \\
\hline & & Spain & 90 & $0.66(1.53)$ & $0.00(0.00)$ & \multirow[b]{2}{*}{$0.343 \S$} & 90 & $0.19(0.75)$ & $0.00(0.00)$ & \multirow[b]{2}{*}{$0.355^{\S}$} & $15(16.7)$ & \\
\hline & & Colombia & 77 & $0.53(1.60)$ & $0.00(0.00)$ & & 77 & $0.43(1.70)$ & $0.00(0.00)$ & & $8(10.4)$ & $0.241^{\S}$ \\
\hline \multirow[t]{4}{*}{$\begin{array}{l}\text { Capnocytophaga } \\
\text { spp. }\end{array}$} & Health and Gingivitis & & 48 & $2.36(2.74)$ & $0.00(5.43)$ & \multirow[b]{2}{*}{0.727} & 48 & $3.30(6.31)$ & $0.00(4.24)$ & \multirow[b]{2}{*}{0.889} & $21(43.8)$ & $1.000 *$ \\
\hline & Periodontitis I-II & & 53 & $2.55(2.77)$ & $0.00(5.30)$ & & 53 & $4.94(11.23)$ & $0.00(4.47)$ & & $25(47.2)$ & $1.000^{\dagger}$ \\
\hline & & Spain & 90 & $0.74(1.68)$ & $0.00(0.00)$ & \multirow[b]{2}{*}{$<0.001 \S$} & 90 & $0.15(0.63)$ & $0.00(0.00)$ & \multirow{2}{*}{$<0.001^{\S}$} & $15(16.7)$ & \\
\hline & & Colombia & 77 & $4.34(2.31)$ & $5.30(1.39)$ & & 77 & $8.83(13.34)$ & $4.17(9.34)$ & & $61(79.2)$ & $<0.001^{\S}$ \\
\hline \multirow{5}{*}{$\begin{array}{l}\text { Actinomyces } \\
\text { odontolyticus }\end{array}$} & Health and Gingivitis & & 48 & $2.24(2.94)$ & $0.00(5.71)$ & \multirow{3}{*}{0.374} & 48 & $6.95(10.96)$ & $0.00(12.56)$ & \multirow{3}{*}{0.278} & $18(37.5)$ & $1.000 *$ \\
\hline & Periodontitis I-II & & 53 & $2.14(2.81)$ & $0.00(5.37)$ & & 53 & $5.82(9.97)$ & $0.00(10.62)$ & & $20(37.7)$ & $0.399^{\dagger}$ \\
\hline & Periodontitis III-IV & & 66 & $2.14(2.81)$ & $4.15(5.63)$ & & 66 & $\begin{array}{c}10.48 \\
(17.67)\end{array}$ & $0.65(16.12)$ & & $34(51.5)$ & $0.414 \ddagger$ \\
\hline & & Spain & 90 & $0.00(0.00)$ & $0.00(0.00)$ & \multirow{2}{*}{$<0.001^{\S}$} & 90 & $0.00(0.00)$ & $0.00(0.00)$ & \multirow{2}{*}{$<0.001 \S$} & $0(0.00)$ & \multirow{2}{*}{$<0.001^{\S}$} \\
\hline & & Colombia & 77 & $5.35(1.59)$ & $5.69(1.24)$ & & 77 & $\begin{array}{c}17.33 \\
(15.95)\end{array}$ & $\begin{array}{c}13.87 \\
(20.47)\end{array}$ & & $72(93.5)$ & \\
\hline
\end{tabular}

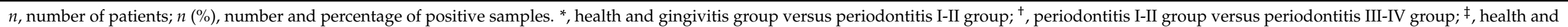
gingivitis group versus periodontitis III-IV group; $\$$, Spain versus Colombia. ${ }^{a}$, Kruskal-Wallis test and Mann-Whitney test. ${ }^{\text {b }}$, chi-square with Bonferroni correction. 


\subsection{Impact of Periodontal Status, Country, Smoking and Age}

The results of the binary logistic regression analyses are presented in Table 6 (only for species showing a reliable model). In the whole cohort, adjusted for country, smoking, periodontal status and age, $P$. gingivalis was significantly associated with Spanish subjects $(\mathrm{OR}=10.48,95 \% \mathrm{CI}[4.59 ; 23.89], p<0.001)$ in stages I-II $(\mathrm{OR}=8.43,95 \% \mathrm{CI}[2.93 ; 24.19]$, $p<0.001)$ and stages III-IV (OR $=3.44,95 \% \mathrm{CI}[1.35 ; 8.78], p=0.010)$ periodontitis. This greater probability of being detected in Spain is shown in the analysis by age strata, although the probability of $P$. gingivalis being detected in subjects from 51 to 60 years is higher in periodontitis groups than in health and gingivitis group. Conversely, P. micra was significantly associated with Colombian subjects $(\mathrm{OR}=8.32,95 \% \mathrm{CI}$ [3.23; 21.45], $p<0.001)$ in health and gingivitis ( $\mathrm{OR}=7.68,95 \% \mathrm{CI}[2.53 ; 23.32], p<0.001)$ and in stages I-II periodontitis ( $\mathrm{OR}=3.41,95 \% \mathrm{CI}[1.15 ; 10.05], p=0.026)$. In addition, the probability of $P$. micra being detected increased in the 30-40-year-old stratum for Colombian subjects $(\mathrm{OR}=10.58,95 \% \mathrm{CI}[2.33 ; 48.04], p=0.002)$ with health and gingivitis $(\mathrm{OR}=18.10,95 \%$ CI [2.39; 137.02], $p=0.005)$ and with stages I-II periodontitis (OR $=7.91,95 \%$ CI [1.25; 49.71], $p=0.027)$. Capnocytophaga spp. had also a higher probability of being detected in Colombia (OR $=19.0,95 \% \mathrm{CI}[8.72 ; 41.63], p<0.001)$, and this probability is maintained in all age strata.

Table 6. Forward stepwise logistic regression analyses evaluating the detection of selected bacterial species considering country, smoking, periodontal status, and age as covariables in a first comparison with the whole cohort, and in a second comparison stratified by age ranges.

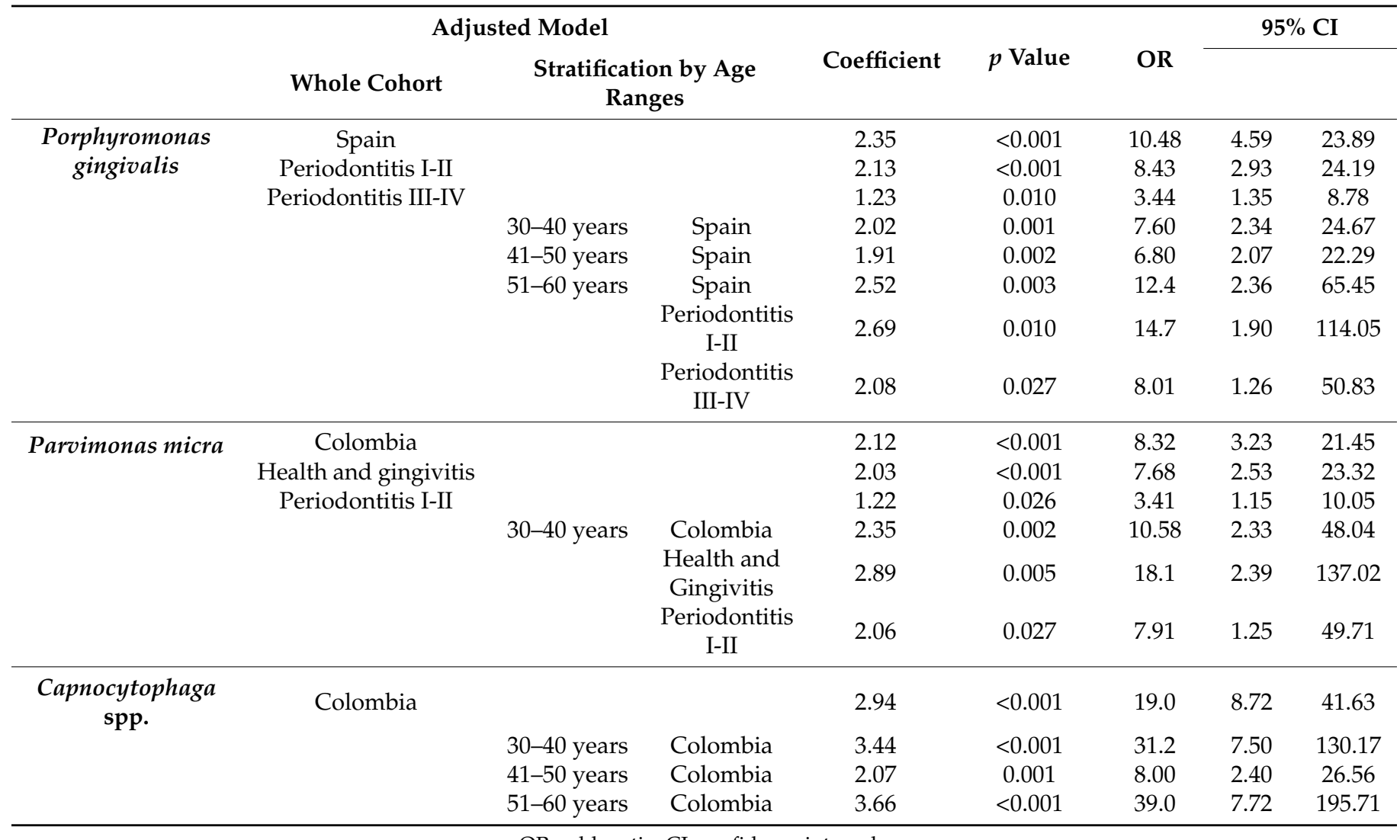

OR, odds ratio; $\mathrm{CI}$, confidence interval.

\section{Discussion}

The present cross-sectional study revealed differences in the subgingival microbiota between periodontitis patients (higher counts and levels of $P$. gingivalis) and healthy/gingivitis subjects (higher levels of E. corrodens and P. micra), while minor differences were observed when comparing different stages of periodontitis. Conversely, relevant differences were 
detected when comparing subjects from different countries, with Colombian subjects harbouring higher total counts and a larger bacterial variability than Spanish patients.

Despite the differences in terms of smoking, also reported in previous studies [13], the studied populations were comparable because the historical trends reinforce that tobacco does not seem to be a determinant in the periodontal status of the studied populations $[5,31]$. Despite this, the impact of smoking on the microbiological results of the present study cannot be ruled out since the impact of tobacco use in periodontitis has been clearly established [32], and may also influence the composition of the subgingival microbiota [33].

The selected populations were also comparable, since they were similar in terms of percentage of periodontal pockets and other clinical variables. All parameters showed, as expected, statistically significant differences among periodontal status groups. However, in Colombia, higher levels of BoP, specifically in periodontitis stages I-II and III-IV, and higher PD in periodontitis stages I-II were evident. In contrast, plaque levels were higher in Spain in the health/gingivitis group. As in previous studies, Colombian patients tended to present more severe clinical findings, with lower plaque levels [13]. It has been suggested that, in Colombian patients, low levels of plaque in deep pockets may be able to trigger high levels of inflammation [16], which may be conditioned by specific lifestyle conditions in developing countries [17] or by a specific genetic background in these patients [34].

Overall, the subgingival microbiota demonstrated differences between subjects with periodontal health/gingivitis (higher prevalence of E. corrodens and P. micra) and periodontitis (higher prevalence of $P$. gingivalis). While the pathogenic role of $P$. gingivalis has been clearly established as a bacterial species strongly associated with periodontitis [30], the findings for E. corrodens and P. micra are unexpected, especially for P. micra, which has also been considered as a periodontal pathogen with a moderate association with periodontitis [30,35-37].

The subgingival microbiota showed clear differences when comparing countries: Colombia, in addition to presenting higher total counts than Spain, also showed significantly higher counts, proportions, and frequency of detection of T. forsythia, P. micra, Capnocytophaga spp., A. odontolyticus, and P. intermedia; conversely, significant higher counts, proportions, and frequency of detection of $P$. gingivalis and C. rectus were found in Spain. Colombian subjects harboured higher prevalence of $P$. micra in health/gingivitis and in periodontitis stages I-II., while in Spain, higher frequencies of detection of $P$. gingivalis were observed in periodontitis stages I-II and III-IV. When also considering age stratum, P. micra showed a stronger association with Colombian patients in health/gingivitis and periodontitis stages I-II groups between 30 and 40 years of age. These findings suggest that the microbiota of Colombian subjects is characterized by higher bacterial counts and larger variability, while a relevant role of $P$. gingivalis in periodontitis was observed in Spanish patients, in agreement with previous studies $[13,19]$. A possible hypothesis may suggest that, in Colombian subjects, dysbiotic biofilms could be associated with larger amounts and greater variety in the microbiota at specific ages [38], while in Spain, the impact of key pathogens could be more relevant [39,40], regardless of age. Conducting longitudinal studies are, therefore, justified to test this hypothesis, and to better understand the possible clinical relevance and the possible impact of using microbiological diagnosis in the context of personalized medicine.

The detected differences in the periodontal microbiota between countries, according to periodontal status, could be related to the influence of specific characteristics of different geographic populations on the bacterial composition $[13,16,19,41,42]$. Furthermore, the 2018 classification of periodontitis does not include different types of periodontitis but rather a single multidimensional entity [23], which might be associated with different microbial profiles when comparing populations.

Thus, specific treatments and therapeutic strategies may be selected for each profile (personalized medicine).

The present study has used culture techniques to evaluate the subgingival microbiota. As explained earlier, the exclusive use of molecular techniques could result in incom- 
plete data on microbial diversity and, therefore, it is important to have parallel culture libraries $[7,20]$. In addition, with the introduction of more competent anaerobic handling and incubation procedures, the culture is reinvented every day [17], and it can be still considered as a relevant tool in the characterization of periodontal pathogens $[22,43,44]$. Microbiological culturing is not free of limitations [7,22], but it continues to be the gold standard for bacterial identification and the starting point for current molecular analyses $[7,22]$. However, bacterial culture is not capable of identifying some segments of the microbiota.

Other limitations of the present study should be acknowledged: the microbiological analysis of the study samples was carried out in parallel in two independent laboratories, although they were trained and calibrated in bacterial culture [13,19,41]; the relatively small sample size; and the differences in demographic (e.g., smoking) and clinical characteristics (plaque or bleeding levels) of the population studied. In addition, no information on socioeconomic status was recorded, and patients were exclusively recruited at university clinics.

\section{Conclusions}

The present analysis, using the criteria of the 2018 classification, has observed significant differences when comparing the subgingival microbiota between periodontitis (higher levels of $P$. gingivalis) and health/gingivitis (higher levels of E. corrodens and $P$. micra), with minor differences between stages of periodontitis. Differences were also detected between countries, with Colombia showing larger bacterial counts and variability of bacterial species: P. gingivalis and C. rectus were the most relevant pathogens in Spain, while T. forsythia, P. micra, P. intermedia, F. nucleatum, A. odontolyticus, and Capnocytophaga spp. were the most prevalent in Colombia.

Supplementary Materials: The following are available online at https:/ /www.mdpi.com/article/10 .3390 /microorganisms $9091940 / \mathrm{s} 1$, Table S1: Distribution of periodontitis grades by country. Table S2: Clinical characteristics of the selected sites for subgingival sampling. Table S3: Mean and standard deviation (SD) and median and interquartile range (IR) of counts (log transformed), proportions and frequencies of detection of target bacterial species according to country, in periodontitis in stages I-II patients. Table S4: Mean and standard deviation (SD) and median and interquartile range (IR) of counts (log transformed), proportions and frequencies of detection of target bacterial species according to country, in periodontitis in stages III-IV patients. Table S5: Mean and standard deviation (SD) and median and interquartile range (IR) of counts (log transformed), proportions and frequencies of detection of target bacterial species, according to country, in health and gingivitis subjects.

Author Contributions: Conceptualization, R.P., G.I.L., and D.H.; patient recruitment and sampling, R.P., M.I.; microbiological analyses, R.P., D.M.C.; validation, M.I., G.I.L., M.S. and D.H.; formal analysis, R.P., M.I. and D.H.; writing — original draft preparation, R.P., M.I., M.S. and D.H.; writingreview and editing R.P., M.I., M.S. and D.H.; supervision, G.I.L., M.S. and D.H.; project administration, R.P., M.I., G.I.L. and D.H.; funding acquisition, R.P., G.I.L., M.S. and D.H. All authors have read and agreed to the published version of the manuscript.

Funding: This work was supported by MINCIENCIAS/Colombia (grant number 130880763942), and Cátedra Extraordinaria Dentaid de Investigación en Periodoncia, University Complutense of Madrid, Spain.

Institutional Review Board Statement: The study was conducted in accordance with the Declaration of Helsinki of the World Medical Association (2008) and approved by the Research Ethics Committees in Spain (reference 18/127-E) and in Colombia (reference 012-2018).

Informed Consent Statement: Informed consent was obtained from all subjects involved in the study.

Data Availability Statement: Data available on request due to restrictions. Data presented in this study are available on request from the corresponding author. The data are not publicly available due to privacy and ethical issues.

Acknowledgments: We are grateful to the Faculties of Dentistry and to the microbiology laboratories of both, the Complutense University of Madrid and El Bosque University. Thanks to Ministerio de Ciencia, Tecnología e Innovación-MINCIENCIAS, Colombia (grant number 130880763942), and 
Cátedra Extraordinaria Dentaid de Investigación en Periodoncia, Complutense University of Madrid, Spain, for having supported the present study.

Conflicts of Interest: The authors declare no conflict of interest.

\section{References}

1. Caton, J.G.; Armitage, G.; Berglundh, T.; Chapple, I.L.C.; Jepsen, S.; Kornman, K.S.; Mealey, B.L.; Papapanou, P.N.; Sanz, M.; Tonetti, M.S. A new classification scheme for periodontal and peri-implant diseases and conditions-Introduction and key changes from the 1999 classification. J. Clin. Periodontol. 2018, 45 (Suppl. 20), S1-S8. [CrossRef]

2. Papapanou, P.N.; Sanz, M.; Buduneli, N.; Dietrich, T.; Feres, M.; Fine, D.H.; Flemmig, T.F.; Garcia, R.; Giannobile, W.V.; Graziani, F.; et al. Periodontitis: Consensus report of workgroup 2 of the 2017 World Workshop on the Classification of Periodontal and Peri-Implant Diseases and Conditions. J. Clin. Periodontol. 2018, 45 (Suppl. 20), S162-S170. [CrossRef] [PubMed]

3. Abusleme, L.; Hoare, A.; Hong, B.Y.; Diaz, P.I. Microbial signatures of health, gingivitis, and periodontitis. Periodontol. 2000 2021, 86, 57-78. [CrossRef]

4. Curtis, M.A.; Díaz, P.I.; Van Dyke, T.E. The role of the microbiota in periodontal disease. Periodontol. 2000 2020, 83, 14-25. [CrossRef] [PubMed]

5. Carasol, M.; Llodra, J.C.; Fernandez-Meseguer, A.; Bravo, M.; Garcia-Margallo, M.T.; Calvo-Bonacho, E.; Sanz, M.; Herrera, D. Periodontal conditions among employed adults in Spain. J. Clin. Periodontol. 2016, 43, 548-556. [CrossRef] [PubMed]

6. Kassebaum, N.J.; Bernabe, E.; Dahiya, M.; Bhandari, B.; Murray, C.J.; Marcenes, W. Global burden of severe periodontitis in 1990-2010: A systematic review and meta-regression. J. Dent. Res. 2014, 93, 1045-1053. [CrossRef] [PubMed]

7. Teles, R.; Teles, F.; Frias-Lopez, J.; Paster, B.; Haffajee, A. Lessons learned and unlearned in periodontal microbiology. Periodontol. 2000 2013, 62, 95-162. [CrossRef]

8. Holt, S.C.; Ebersole, J.L. Porphyromonas gingivalis, Treponema denticola, and Tannerella forsythia: The "red complex", a prototype polybacterial pathogenic consortium in periodontitis. Periodontol. 2000 2005, 38, 72-122. [CrossRef]

9. Haffajee, A.D.; Bogren, A.; Hasturk, H.; Feres, M.; Lopez, N.J.; Socransky, S.S. Subgingival microbiota of chronic periodontitis subjects from different geographic locations. J. Clin. Periodontol. 2004, 31, 996-1002. [CrossRef]

10. Socransky, S.S.; Haffajee, A.D. Periodontal microbial ecology. Periodontol. 2000 2005, 38, 135-187. [CrossRef]

11. Hajishengallis, G.; Lamont, R.J. Beyond the red complex and into more complexity: The polymicrobial synergy and dysbiosis (PSD) model of periodontal disease etiology. Mol. Oral Microbiol. 2012, 27, 409-419. [CrossRef] [PubMed]

12. Montenegro, S.C.L.; Retamal-Valdes, B.; Bueno-Silva, B.; Duart, P.M.; Faveri, M.; Figueiredo, L.C.; Feres, M. Do patients with aggressive and chronic periodontitis exhibit specific differences in the subgingival microbial composition? A systematic review. $J$. Periodontol. 2020, 91, 1520. [CrossRef]

13. Herrera, D.; Contreras, A.; Gamonal, J.; Oteo, A.; Jaramillo, A.; Silva, N.; Sanz, M.; Botero, J.E.; Leon, R. Subgingival microbial profiles in chronic periodontitis patients from Chile, Colombia and Spain. J. Clin. Periodontol. 2008, 35, 106-113. [CrossRef] [PubMed]

14. Albandar, J.M. Epidemiology and risk factors of periodontal diseases. Dent. Clin. N. Am. 2005, 49, 517-532. [CrossRef] [PubMed]

15. Feres, M.; Teles, F.; Teles, R.; Figueiredo, L.C.; Faveri, M. The subgingival periodontal microbiota of the aging mouth. Periodontol. 2000 2016, 72, 30-53. [CrossRef] [PubMed]

16. Botero, J.E.; Contreras, A.; Lafaurie, G.; Jaramillo, A.; Betancourt, M.; Arce, R.M. Occurrence of periodontopathic and superinfecting bacteria in chronic and aggressive periodontitis subjects in a Colombian population. J. Periodontol. 2007, 78, 696-704. [CrossRef] [PubMed]

17. Contreras, A.; Moreno, S.M.; Jaramillo, A.; Pelaez, M.; Duque, A.; Botero, J.E.; Slots, J. Periodontal microbiology in Latin America. Periodontol. 2000 2015, 67, 58-86. [CrossRef] [PubMed]

18. Minguez, M.; Pousa, X.; Herrera, D.; Blasi, A.; Sanchez, M.C.; Leon, R.; Sanz, M. Characterization and serotype distribution of Aggregatibacter actinomycetemcomitans isolated from a population of periodontitis patients in Spain. Arch. Oral Biol. 2014, 59, 1359-1367. [CrossRef]

19. Sanz, M.; van Winkelhoff, A.J.; Herrera, D.; Dellemijn-Kippuw, N.; Simon, R.; Winkel, E. Differences in the composition of the subgingival microbiota of two periodontitis populations of different geographical origin. A comparison between Spain and The Netherlands. Eur. J. Oral Sci. 2000, 108, 383-392. [CrossRef]

20. Donachie, S.P.; Foster, J.S.; Brown, M.V. Culture clash: Challenging the dogma of microbial diversity. ISME J. 2007, 1, 97-99. [CrossRef]

21. Tomšič, K.; Rodič, K.; Sotošek, A.; Videmšek, P.; Seme, K.; Herrera, D.; Sanz, M.; Gašperšič, R. Do Differences in Cultivable Subgingival Species Exist between Different Periodontitis Stages and Grades? Oral Health Prev. Dent. 2021, 19, 15-24. [CrossRef]

22. Tanner, A.C. Anaerobic culture to detect periodontal and caries pathogens. J. Oral Biosci. 2015, 57, 18-26. [CrossRef]

23. Tonetti, M.S.; Greenwell, H.; Kornman, K.S. Staging and grading of periodontitis: Framework and proposal of a new classification and case definition. J. Clin. Periodontol. 2018, 45 (Suppl. 20), S149-S161. [CrossRef]

24. Von Elm, E.; Altman, D.G.; Egger, M.; Pocock, S.J.; Gotzsche, P.C.; Vandenbroucke, J.P.; Initiative, S. The Strengthening the Reporting of Observational Studies in Epidemiology (STROBE) Statement: Guidelines for reporting observational studies. Int. J. Surg. 2014, 12, 1495-1499. [CrossRef] 
25. Chapple, I.L.C.; Mealey, B.L.; Van Dyke, T.E.; Bartold, P.M.; Dommisch, H.; Eickholz, P.; Geisinger, M.L.; Genco, R.J.; Glogauer, M.; Goldstein, M.; et al. Periodontal health and gingival diseases and conditions on an intact and a reduced periodontium: Consensus report of workgroup 1 of the 2017 World Workshop on the Classification of Periodontal and Peri-Implant Diseases and Conditions. J. Clin. Periodontol. 2018, 45 (Suppl. 20), S68-S77. [CrossRef] [PubMed]

26. Badersten, A.; Nilveus, R.; Egelberg, J. Effect of nonsurgical periodontal therapy. VII. Bleeding, suppuration and probing depth in sites with probing attachment loss. J. Clin. Periodontol. 1985, 12, 432-440. [CrossRef]

27. O'Leary, T.J.; Drake, R.B.; Naylor, J.E. The plaque control record. J. Periodontol. 1972, 43, 38. [CrossRef]

28. Syed, S.A.; Loesche, W.J. Survival of human dental plaque flora in various transport media. Appl. Microbiol. 1972, 24, 638-644. [CrossRef]

29. Alsina, M.; Olle, E.; Frias, J. Improved, low-cost selective culture medium for Actinobacillus actinomycetemcomitans. J. Clin. Microbiol. 2001, 39, 509-513. [CrossRef] [PubMed]

30. Van Winkelhoff, A.J.; Loos, B.G.; van der Reijden, W.A.; van der Velden, U. Porphyromonas gingivalis, Bacteroides forsythus and other putative periodontal pathogens in subjects with and without periodontal destruction. J. Clin. Periodontol. 2002, 29, 1023-1028. [CrossRef] [PubMed]

31. Ministerio de Salud y Protección Social de Colombia. IV Estudio Nacional de Salud Bucal (ENSAB IV) 2014. Available online: https:/ / www.minsalud.gov.co/sites/rid/Lists/BibliotecaDigital/RIDE/VS/PP/ENSAB-IV-Situacion-Bucal-Actual.pdf. (accessed on 28 August 2021).

32. Eke, P.I.; Wei, L.; Thornton-Evans, G.O.; Borrell, L.N.; Borgnakke, W.S.; Dye, B.; Genco, R.J. Risk Indicators for Periodontitis in US Adults: NHANES 2009 to 2012. J. Periodontol. 2016, 87, 1174-1185. [CrossRef]

33. van Winkelhoff, A.J.; Bosch-Tijhof, C.J.; Winkel, E.G.; van der Reijden, W.A. Smoking affects the subgingival microflora in periodontitis. J. Periodontol. 2001, 72, 666-671. [CrossRef] [PubMed]

34. Loos, B.G.; John, R.P.; Laine, M.L. Identification of genetic risk factors for periodontitis and possible mechanisms of action. J. Clin. Periodontol. 2005, 32 (Suppl. 6), 159-179. [CrossRef] [PubMed]

35. Rams, T.E.; Feik, D.; Listgarten, M.A.; Slots, J. Peptostreptococcus micros in human periodontitis. Oral Microbiol. Immunol. 1992, 7, 1-6. [CrossRef]

36. Kremer, B.H.; Loos, B.G.; van der Velden, U.; van Winkelhoff, A.J.; Craandijk, J.; Bulthuis, H.M.; Hutter, J.; Varoufaki, A.S.; van Steenbergen, T.J. Peptostreptococcus micros smooth and rough genotypes in periodontitis and gingivitis. J. Periodontol. 2000, 71, 209-218. [CrossRef]

37. Van Dalen, P.J.; van Winkelhoff, A.J.; van Steenbergen, T.J. Prevalence of Peptostreptococcus micros morphotypes in patients with adult periodontitis. Oral Microbiol. Immunol. 1998, 13, 62-64. [CrossRef]

38. Hajishengallis, G. The inflammophilic character of the periodontitis-associated microbiota. Mol. Oral Microbiol. 2014, 29 , $248-257$. [CrossRef] [PubMed]

39. Hajishengallis, G.; Diaz, P.I. Porphyromonas gingivalis: Immune subversion activities and role in periodontal dysbiosis. Curr. Oral Health Rep. 2020, 7, 12-21. [CrossRef]

40. Lamont, R.J.; Koo, H.; Hajishengallis, G. The oral microbiota: Dynamic communities and host interactions. Nat. Rev. Microbiol. 2018, 16, 745-759. [CrossRef]

41. Lafaurie, G.I.; Contreras, A.; Baron, A.; Botero, J.; Mayorga-Fayad, I.; Jaramillo, A.; Giraldo, A.; Gonzalez, F.; Mantilla, S.; Botero, A.; et al. Demographic, clinical, and microbial aspects of chronic and aggressive periodontitis in Colombia: A multicenter study. J. Periodontol. 2007, 78, 629-639. [CrossRef]

42. Mayorga-Fayad, I.; Lafaurie, G.I.; Contreras, A.; Castillo, D.M.; Baron, A.; Aya Mdel, R. Subgingival microbiota in chronic and aggressive periodontitis in Bogota, Colombia: An epidemiological approach. Biomedica 2007, 27, 21-33. [CrossRef] [PubMed]

43. Van Winkelhoff, A.J.; Rurenga, P.; Wekema-Mulder, G.J.; Singadji, Z.M.; Rams, T.E. Non-oral gram-negative facultative rods in chronic periodontitis microbiota. Microb. Pathog. 2016, 94, 117-122. [CrossRef] [PubMed]

44. Vartoukian, S.R.; Moazzez, R.V.; Paster, B.J.; Dewhirst, F.E.; Wade, W.G. First cultivation of health-associated Tannerella sp. HOT-286 (BU063). J. Dent. Res. 2016, 95, 1308-1313. [CrossRef] [PubMed] 